\title{
Effect of Starch on the Mechanical and Rheological Properties of Polypropylene
}

\author{
M. K. Oduola, P. O. Akpeji \\ Department of Chemical Engineering, University of Port Harcourt, Port Harcourt, NIGERIA
}

Email address:

koyejo.oduola@uniport.edu.ng (M. K. Oduola)

To cite this article:

M. K. Oduola, P. O. Akpeji. Effect of Starch on the Mechanical and Rheological Properties of Polypropylene. American Journal of Chemical Engineering. Vol. 3, No. 2-1, 2015, pp. 1-8.doi: 10.11648/j.ajche.s.2015030201.11

\begin{abstract}
Blends of starch (tapioca) and polypropylene were prepared in various wt/wt concentrations ranging from $100 \%$ polypropylene resins to 5:95, 10:90, 20:80, 30:70, 40:60, and 50:50 wt \% starch to $\mathrm{wt} \%$ polypropylene blends. Then the rheological and mechanical properties of the resulting blends were determined using Plastometer and Universal Testing Machine respectively. Tensile strength, percentage elongation, flexural modulus, Izod impact, vicat softening temperature and melt flow index tests were carried out according to American standard for testing and materials procedure. The melt flow index was found to decrease linearly with increasing starch concentrations up to $30 \mathrm{wt} \%$ starch to $\mathrm{wt} \%$ plastic, beyond which no flow was observed. The presence of starch in polypropylene was found to have positive effect on some of the mechanical properties like flexural modulus and Izod impact strength, whereas a negative impact was obtained on the tensile strength and percentage elongation. It was observed that higher starch loadings above 30\% reduced the mechanical properties while lower starch loadings below 30\% improved some mechanical properties. In addition, higher starch loadings above $30 \%$ does not favor the melt flow index and the Izod impact strength since there was no flow due to lower vicat softening temperature. Thus, with the aid of controlled incorporation of the starch additive, several properties of the modified polypropylene specimen could be enhanced.
\end{abstract}

Keywords: Polypropylene, Rheology, Polymer Blends, Mechanical Properties, Starch, Compatibilization

\section{Introduction}

An issue of pertinent importance emerging in recent years is the economic development on one hand and sustainability of the world on the other hand. While numerous new products especially plastics are increasingly developed, the wastes resulting from their processing, usage and disposal pose a major threat to the environment because of their non-degradability and resistance to most micro-organisms. The time necessary for many a synthetic polymer to fully decompose is estimated to be around 500 years, meaning that during the long interim natural phenomena would be influenced by the presence of these materials. As a consequence, numerous attempts have been made to devise new ways of producing green polymers, especially from natural sources such as starch [1-10]. The high price of the crude oil employed to a large extent as raw material in making conventional plastics is an additional impetus.

Plastics have been applied in the large majority of short-life products due to some of their attractive characteristics such as low specific weight, mechanical resistance, a trouble-free processability and considerable durability. Collaborators still consider that resistance to external agents, the photo-oxidative degradation and to the microbiological attack have led these polymeric materials to a highlighted position in the transformation industries nowadays [8, 10-16].

In particular, the market size of polypropylene (PP) plastic is currently over 100 billion pounds globally while the duration of life of its products is very small (roughly $40 \%$ have duration of life less than a month). Therefore, the enormous production and utilization of this plastic and polymers in general lead to their accumulation in the environment. Since plastics are not easily degraded by micro organisms, there is a vast waste stream (approximately 25 million tons for 2013) that reaches each year to the final recipients creating serious environmental problems. Today, plastics have become a serious source of pollution affecting both flora and fauna $[1-3,9,10,17]$.

Waste disposal has therefore become a major concern because of the scarcity of acceptable waste disposal sites accompanied by an increasing amount of waste. Plastics comprise about $18 \%$ of municipal solid waste and are among the most visible and the least degradable. Though these plastics can be recycled, the process is complex and has one major 
drawback: the materials are degraded by use and by the recycling process. The thermal and mechanical properties of recycled materials are inferior to those of virgin products. The recycled materials must therefore be treated and re-stabilized. A vast majority of these are therefore disposed in landfills where they accumulate due to their resistance to degradation $[2,18-21]$.

Since their inception, the majority of commodity polymeric materials, such as packaging and bottles, have been derived from non-renewable petroleum sources. Therefore, the integration of naturally occurring materials, such as starch, into commodity plastics has been a welcome development in recent years. Starch can also be blended with biodegradable polymers to decrease the cost of the material. In cases of blends with petroleum-based polymers, the integration of starch will also decrease dependence on non-renewable resources [2, 4, 22-25].

Starch has thus been used for many years as an additive to plastic for various purposes [3]. Starch is an abundant, naturally occurring polysaccharide that is obtained from various plant sources, such as corn, potato, rice and cassava. It is commonly used to blend PP powder owing to its crystalline structure, physical properties similar to polyolefin, as well as its sufficient thermal stability up to $265^{\circ} \mathrm{C}$. However, the issues around its use have been that it is hydrophilic in nature, unlike polyolefin.

The starch molecule as a semi-crystalline polymer is made up of glucose monomer units with two important functional groups, the $-\mathrm{OH}$ group that is susceptible to substitution reactions and the $\mathrm{C}-\mathrm{O}-\mathrm{C}$ bond that is susceptible to chain breakage (Fig. 1). By reaction of its $-\mathrm{OH}$ group, modification of various properties can be obtained. In its application in biodegradable plastics, starch is either physically mixed in with its native granules and kept intact, or melted and blended on a molecular level with the appropriate polymer. In either form, the fraction of starch in the mixture which is accessible to enzymes can be degraded by either, or both, amylases and glycosidase [3,4, 10,24-29].

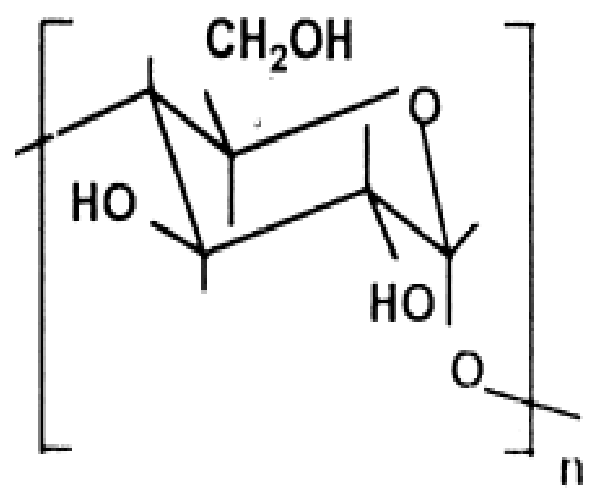

Figure 1. Starch structure

In this manner, studies have been conducted on the incorporation of biodegradable polymers, such as the starch, to the traditional polyolefins, which is justified by the presence of hydrolysable groups in the natural polymer molecules that are capable of inducing the biodegradation of the polyolefins [1]. Considerable amount of polyolefin waste have thus been reduced through the induction of a certain level of biodegradability by adding biodegradable additives in the form of master batches and/or pro-oxidants. The most commonly employed additives are made of starch and other components.

Each additive has a definite role, starting from polymer manufacturing to storage, transportation, processing and final applications. They can be added directly or as a solution in a suitable solvent or in the form of master-batch. Additives are incorporated in PP, both to ease processing as well as to improve some desired properties. The types and amount of additives used determine how well the resin processes. If the additive level is insufficient, it can lead to melt flow break during extrusion, leading to deterioration in physical properties of the final product. Inappropriate addition of additives can lead to problems like yellowing, gas fading and pinking [18-20].

As stated previously, starch can be blended with non-biodegradable polymers to render the blend partially biodegradable, and with biodegradable polymers to decrease the cost of the material. Blends of starch with other renewable or non-renewable thermoplastics can possess excellent mechanical properties and depending on the blend components, starch blends may or may not be degradable. Dry granular starch, by itself, cannot be processed like a plastic; however, it can be heated and blended with several different small polar molecules (water, glycerol) or polar oligomers (polyols), giving a thermoplastic material generally called Thermoplastic Starch or Plasticized Starch. This process, known as gelatinization, breaks up the granular structure of starch by disrupting hydrogen bonding between adjacent glucose molecules and essentially destroys its crystallinity. Starch has been reported to have been processed by a variety of processing operations routine in the plastics industry including kneading, extrusion, compression moulding and injection moulding [21].

The effect of starch in PP biodegradation was studied by Inherika [24], who concluded that the presence of starch in PP induces changes in its biodegradability depending on the quantity of starch introduced. Higher starch a loading above $30 \%$ caused more degradation but reduced the mechanical strength and lower starch loadings below 30\% improved mechanical strength but might not be sufficient to cause biodegradation. Thus, below 30\% starch content, mechanical properties of the polymer will still be favorable and degradation can also occur.

As a biodegradable filler in low density polyethylene (LDPE), it was reported that a starch-filled LDPE became porous after the extraction of the starch [22]. This porous film can be readily invaded by microorganisms and rapidly saturated with oxygen, thereby increasing polymer degradation by biological and oxidative pathways. When starch is blended with PP, the starch content is readily degraded by micro-organisms causing pore spaces in the resulting product and reducing the long chain molecular structure of polymers which makes it easier for the bacteria and fungi to digest the 
molecular structure.

Table 1. Some typical mechanical properties of polypropylene (PP) [10,20,25]

\begin{tabular}{|c|c|c|c|c|c|}
\hline ASTM or UL Test & Property & HPP* & HPP-filled & CPP** & CPP-filled \\
\hline D792 & Specific gravity & $0.90-0.91$ & $0.97-1.27$ & $0.89-0.91$ & $0.98-1.24$ \\
\hline D570 & Water absorption (\%) & $0.01-0.03$ & $0.01-0.09$ & 0.03 & $0.01-0.02$ \\
\hline D638 & Tensile strength $\left(10^{3} \mathrm{psi}\right)$ & $4.5-6.0$ & $3.5-16.0$ & $4.0-5.5$ & $2.5-10.0$ \\
\hline D638 & Elongation at break (\%) & $100-600$ & $1.5-80$ & $200-500$ & $2.2-50$ \\
\hline D638 & Tensile modulus $\left(10^{3} \mathrm{psi}\right)$ & $16.5-22.5$ & $37.5-100$ & $13.0-18.0$ & $5-35$ \\
\hline D790 & Flexural modulus $\left(10^{3} \mathrm{psi}\right)$ & $17-25$ & $21-100$ & $13-20$ & $21-96$ \\
\hline D256 & $\begin{array}{l}\text { Impact strength, Izod } \\
\text { (ft-lb/in of notch) }\end{array}$ & $0.4-1.4$ & $0.6-12$ & $1.1-14$ & $0.6-4.0$ \\
\hline D785 & Hardness, Rockwell R & $80-102$ & $75-117$ & $65-96$ & $81-105$ \\
\hline C177 & 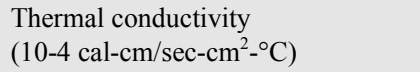 & 2.8 & $2.4-9$ & $3.5-4.0$ & $3-9$ \\
\hline D696 & $\begin{array}{l}\text { Coefficient of thermal expansion } \\
\left(10-5 \text { in } / \text { in }-{ }^{\circ} \mathrm{C}\right)\end{array}$ & $8-10$ & $1.5-5$ & $6-10$ & $2-6$ \\
\hline \multirow[t]{2}{*}{ D648 } & Deflection temperature $\left({ }^{\circ} \mathrm{F}\right)$ & & & & \\
\hline & At $264 \mathrm{psi}$ & $120-140$ & $130-330$ & $120-140$ & $116-280$ \\
\hline UL 94 & UL flammability rating $* * *$ & $\mathrm{HB}$ & $\mathrm{HB}$ & $\mathrm{HB}$ & $\mathrm{HB}$ \\
\hline
\end{tabular}

*Homopolymer polypropylene. **Copolymer polypropylene.

Hamdan et al. [23] investigated the compatibility studies of PP-Sago Starch (SS) blends using dynamic mechanical thermal analysis (DMTA). Sago starch (SS) was melt-blended with PP with the concentration of SS in the blends varied between $10 \%$ and $50 \%$ by weight. Characterization of the $\mathrm{PP} / \mathrm{SS}$ blends was carried out to gain some information on the miscibility between PP and SS and to gain insight into how well these materials behave thermodynamically with regard to the variation of the storage modulus $\left(\mathrm{E}^{\prime}\right)$ and the loss tangent $(\tan \delta)$ with temperature. The $E^{\prime}$ and $\tan \delta$ remained unchanged for SS concentration between $10 \%$ to $33 \%$ but increased as SS content reached $50 \%$. The blend containing $50 \% \mathrm{SS}$ was superior as compared to the other blends in the DMTA measurements. Through the use of a Differential Scanning Calorimeter (DSC), the melting endotherm of the miscible blends was found to increase constantly with increasing SS content, while the tensile properties of the blends decreased with SS content. Examination of the blends with a Scanning Electron Microscope (SEM) showed that the SS granules were well dispersed in the PP matrix.

Ogah and Afiukwa [26] studied the effects of starch blend on the mechanical properties and biodegradability of PP. The effect of corn and cassava starch blends on PP mechanical properties and biodegradability was studied using the gravimetric (weight loss) method. The results showed that tensile strength of the polymer decreased progressively from 2.497 $\mathrm{MPa}$ of pure polymer to $0.250 \mathrm{MPa}$ for corn starch $(90 \%$ weight loss) and $0.500 \mathrm{MPa}$ for cassava starch ( $80 \%$ weight loss) each at $50 \%$ starch addition. At the same rate, elongation at break also decreased from $1.087 \%$ of pure polymer to $0.10 \%$ for corn starch (91\% weight loss) and $0.15 \%$ for cassava starch ( $86 \%$ weight loss). The biodegradability of a $10 \%$ starch filled polymer composite within 30 days incubation was enhanced by more than $70 \%$ in the presence of the micro-organism and it increased with incubation period.

Upon investigation of the morphology-mechanical property relationship of $\mathrm{PP} /$ starch blends $[29,30]$ using SEM, the blends were found to be immiscible with distinct polymer-starch domains at high starch volume fractions $(85 \%$ $\mathrm{PP} / 15 \%$ starch $\rightarrow 87.5 \% \mathrm{PP} / 12.5 \%$ starch), which gradually showed the morphology of well dispersed miscible blends at lower starch volume fractions (from $2.5 \% \rightarrow 10 \%$ starch) The starch domains exhibited characteristic voids which could be due to thermal degradation at the processing temperatures employed. The mechanical properties of the blends and viscosity of the blends decrease with increasing starch volume fractions.

In this study we describe investigations into the effect of starch additive at various starch to PP weight ratios on the rheological and mechanical properties of the resulting blends.

\section{Materials and Methods}

\section{Materials}

Locally made cassava starch (tapioca) precipitated in water was bought at a local market (Nchia-Eleme, Rivers State, NIGERIA). PP powder of grade HPIG 110 (H- Homopolymer, P- Polypropylene, I- Injection moulding, G- General purpose additive) was gotten at Indorama Eleme Petrochemicals Limited, Port Harcourt, before the addition of stabilizers and additives. Both the starch and polypropylene were used without prior treatment.

\section{Starch Preparation \& Blending}

The starch bought contained water which had to be removed because the presence of moisture in the starch would cause the starch to gelatinize easily once heated. The starch was first aired by putting it in the sun to remove water content before drying completely in an oven at about $50^{\circ} \mathrm{C}$. Then the dried starch had lumps which were grinded and sieved using a $1 \mathrm{~mm}$ mesh size filter. The resulting starch was powdery and easy flowing.

Starch and PP (HPIG 110) (2 kg total) were weighted and 
blended in the appropriate wt PP/wt starch ratios $(95: 5 ; 90: 10$; 80:20, 70:30; 60:40 and 50:50) using a mixer. The starch and polymer were first weighed separately to their appropriate masses and poured into the mixer. Starch was added as filler to various resins to make films or moulded materials impermeable to water.

\section{Extrusion and Moulding of Blends}

The resulting starch/PP blends were formed into test specimens of dumb-bell shape by ASTM standard using an injection moulding machine (Fig. 3a). The temperatures used for zones 1 and 2 were $135^{\circ} \mathrm{C}$ and $160^{\circ} \mathrm{C}$ respectively. 5 sets of each blend were formed containing 3 pieces each of tensile and flexural testing samples. The moulded blends were put in a humidifier for 48 hours to ensure that the heated particles were compact for better accuracy of the measured values [31].

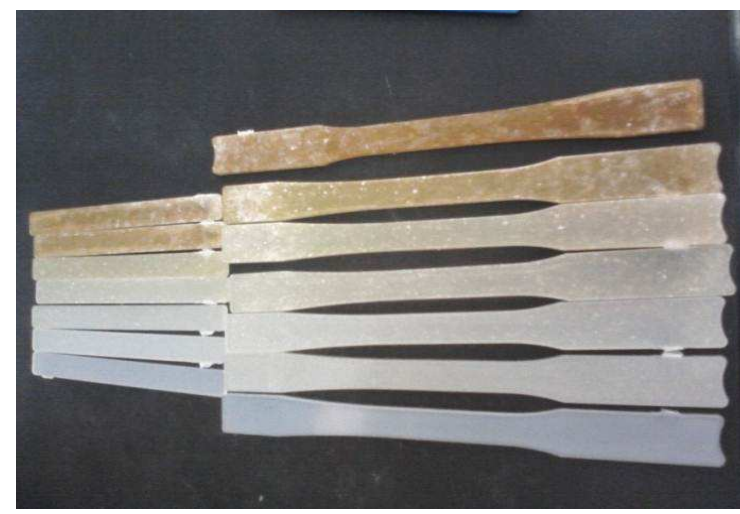

Figure 2. Blends of PP/starch of various wt/wt compositions from $100 \% \mathrm{PP}$ underneath to $50 \mathrm{wt} \% \mathrm{PP} / 50 \mathrm{wt} \%$ starch at the peak.

Melt Flow Index Test: The melt flow index (MFI), measured in $\mathrm{g} / 10 \mathrm{mins}$, is the weight in grams of the material extruded through a standard die $2.095 \mathrm{~mm}$ diameter at $230^{\circ} \mathrm{C}$ and applying a load of 2160 grams for 10 minutes in the piston position. It is an indication of the average molecular weight of the resin or mechanical strength of the materials. The average molecular weight and MFI are inversely proportional, so also it is a rough measure of the inverse of its viscosity. Knowing the MFI of a polymer is vital in anticipating and controlling its processing. Generally, high MFI polymers are used in injection moulding, and lower MFI polymers are used in blow moulding or extrusion processes [5,31]. Tests relating to MFI analysis are done using extrusion plastometer shown in Fig. $3 \mathrm{~b}$ following ASTM D1238.

All mechanical properties tests were carried out in Indorama Eleme Petrochemicals Laboratory, Port Harcourt, Nigeria. The tests were performed on seven different Dumbbells specimens with various blend compositions ranging from $100 \%$ HPIG 110 flakes to $50 \mathrm{wt} \%$ HPIG 110 flakes $/ 50 \mathrm{wt} \%$ starch as shown in Fig. 2.

Flexural test: This is the relative stiffness of the material due to bending stress generated. The higher the flexural modulus, the higher the stiffness of materials, the lower the impact strength. It is a measure of the force required to bend the polymer under 3 point loading condition.

Flexural testing is most commonly carried out in the three- point bending (ASTM D 790) by employing an Instron Universal Testing Machine (UTM). It is generally more convenient than tensile testing to assess the stiffness of rigid materials, but less convenient for stress measurements [20].

Tensile strength test: The tensile strength of a material otherwise known as tensile stress is its ability to resist force that pulls it apart. It is expressed as the force $(\mathrm{F})$ required per unit cross-sectional area (A). Tensile testing using ASTM D638 and equivalents requires dumbbell (dog bone) test specimen. Such test specimen feature a straight zone of uniform cross section (gauge zone), over which the deformation and corresponding stress are uniform and two end tabs of larger cross section, over which the specimen is held (dumbbell or dog bone shape). For PP, test specimens usually have a uniform thickness and the tabs are pinched in no-slip jaws (clamps or grips) attached to the UTM.

Elongation is the ratio of the extension of a material to the length of the material prior to stretching, expressed as a percent. A full stress-strain curve is the ideal way of reporting the tensile behavior, but specific quantities are generally reported, which include the tensile (Young Modulus, E), tensile yield stress, $\sigma_{\mathrm{y}}$ when applicable, the tensile strength at ultimate or at break, $\sigma_{\mathrm{b}}$ and also elongation at yield, $E_{y}$ and at break, $E_{b}$ [25].

Izod impact test: This is a measure of the specimen's resistance to impact from a swinging pendulum using Impact Tester shown in Fig. 3c. The impact strength is the energy per unit length or width of notch for izod tests $(\mathrm{J} / \mathrm{m})$ or $\mathrm{ft}-\mathrm{ibf} / \mathrm{in}$, with $1 \mathrm{KJ} / \mathrm{m}=18.7 \mathrm{ft}-\mathrm{lbf} /$ in. In the izod test (ASTM D $256 \mathrm{~A}$ ), the test specimen is clamped vertically in a vise and struck in a cantilever bending mode [25]. The breaking energy value will appear on the digital display.

$$
\text { I.S }=\frac{E_{a}-E_{S}}{t \times 1000}
$$

where I.S = Impact Strength(Joule/meter); $E_{s}=$ Initial energy set on impact tester $(\mathrm{J})=0.04 \mathrm{~J} ; E_{a}=$ Absorbed energy read on the screen $(\mathrm{J}) ; t=$ Thickness $(\mu \mathrm{m})$.

Vicat softening point: Polymeric materials soften or lose their rigidity when heated. This particular test determines the temperature at which a flat-ended needle of $1 \mathrm{~mm}^{2}$ will penetrate to a depth of $1 \mathrm{~mm}$ in a plastic specimen subjected to a controlled heating rate under fixed load. The softening temperature of the specimens determined using a vicat tester shown in Fig. 3d.

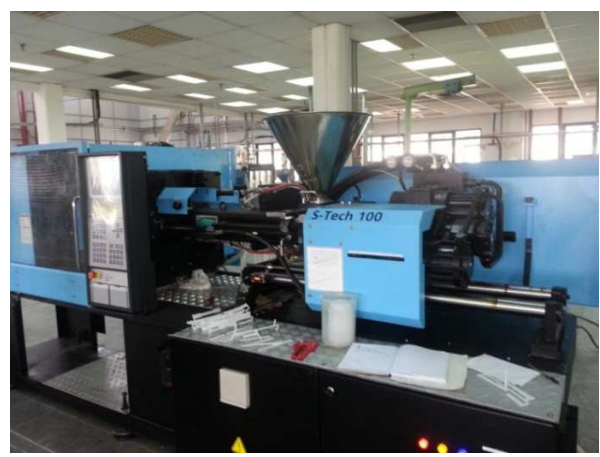

Figure 3a. Injection moulding machine 


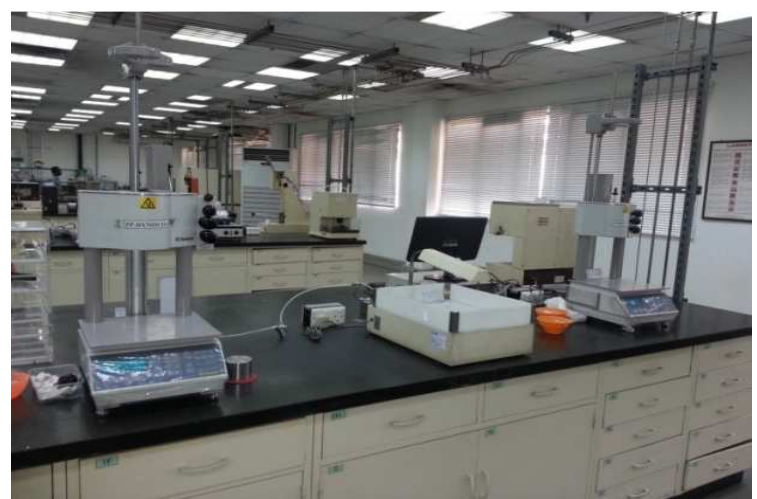

Figure 3b. Extrusion plastometer for MFI analysis.

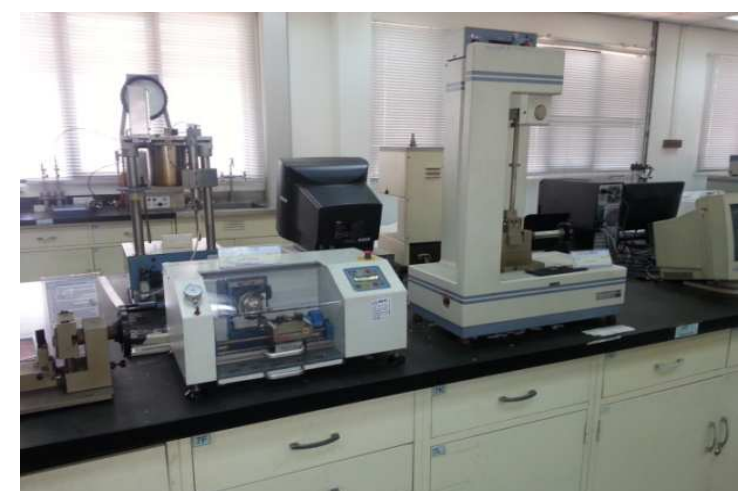

Figure 3c. Izod Impact Tester

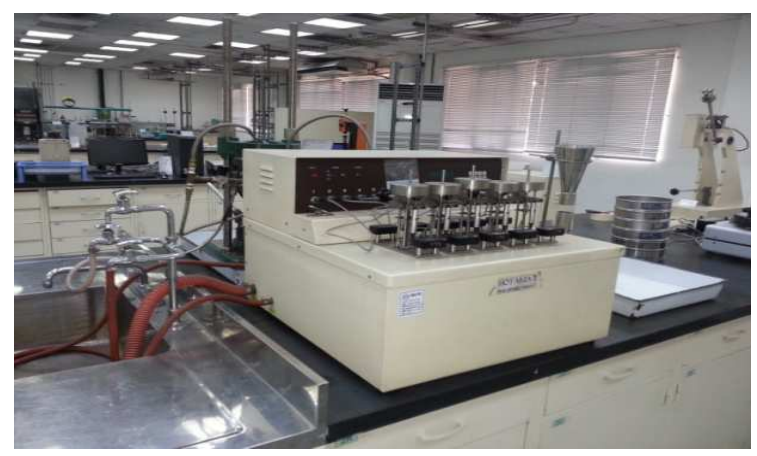

Figure 3d. Vicat Testing Machine

\section{Results and Discussion}

The melt flow index of the virgin polypropylene was investigated in comparison with that of the modified HPIG/starch blends (Fig. 4). It is clearly evident that the MFI decreases with increasing starch concentration which is attributable to increasing of viscosity of the blend which makes the polymer hard to flow, higher molecular weight and higher elasticity. [5]. The observed dependence could be well fitted by a linear equation relating the MFI values as a function of the starch weight fraction in the blend, with a high enough coefficient of determinations $\left(\mathrm{R}^{2}=0.963\right)$. It can also be seen that when the starch concentration exceeds $30 \%$, no MFI value could be deduced due to the fact that the spaces between the particles were small as for higher loading content, hence no flow was observed. The temperature of the specimen is set at the range of $154^{\circ} \mathrm{C}-157^{\circ} \mathrm{C}$ in which there is no flow at $40 / 60 \%$ and 50/50\%. Obviously, the incorporation of starch in HPIG 110 at low quantity weakens the flow rate properties of the flakes while large higher starch quantity in the blends is not favorable for the machine due to blockage.

It can be inferred from the data presented in Table 2 that the Izod impact strength rises rapidly from $5 \%$ starch content to $30 \%$ starch content before it starts to decrease due to high concentration of starch. The Izod impact strength increases as the Vicat Softening Point increases. As a result of low softening temperature observed at $40 / 60 \%$ and $50 / 50 \%$ starch/HPIG 110, the materials could no longer resist sudden load due to high starch content. However, the flexibility of the polymer at higher starch loadings can cause the specimen to break when hammered. Above 30/70\% blends, the impact strength decreases with increase in starch concentration.

Starch and polyolefin blends generally contain low starch content and can display the good mechanical properties. Compatibilized starch blends with both virgin and recycled polyolefins showed improved properties compared with uncompatibilized blends. Particularly, when reactively blending starch with non-renewable polymers, such as polyolefins, a general trend is observed; blend properties began to deviate sharply from the polyolefin properties as starch content was increased past $60 \%$. In these cases, high starch loadings resulted in a large decrease in the tensile strength and modulus and in one case, an increase in elongation of the blends [32-37].

At higher starch loadings in starch/polyolefin blends, mechanical properties are usually poor since the mechanical properties of the starch are dominant. Despite the increasing number of studies on starch blends, there is a lack of publications which explore blends containing large fractions of starch, which is sustainably desirable as a biodegradable renewable blend component. The drawback however is that uncompatibilized blends might suffer from poor adhesion at the interface which leads to poor mechanical properties $[2,3,38]$.

The incorporation of starch reduces the values for tensile strength at yield and at break for PP (Table 3). It can be deduced that the higher the starch concentration in the blend, the lower the value of the tensile strength reached. This can probably be justified by the low tensile strength presented by pure starch, almost $90 \%$ lower than the one presented by PP.

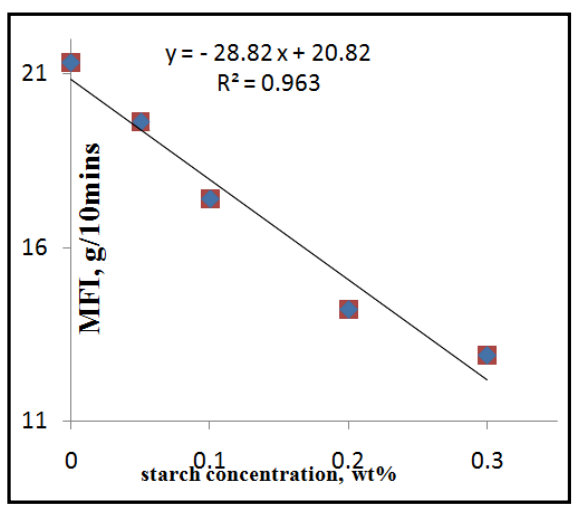

Figure 4. Melt flow index of polypropylene/starch blends at different compositions. 
Table 2.Impact energy and corresponding impact strength of polypropylene samples modified with starch.

\begin{tabular}{lllll}
\hline S/No & HPIG/Starch Content & Thickness $(\boldsymbol{\mu m})$ & Impact Energy $(\mathbf{J})$ & Impact Strength $(\mathbf{J} / \mathbf{m})$ \\
\hline 1 & $100 \%$ HPIG & 3.21 & 0.095 & 17 \\
2 & $5: 95$ & 3.22 & 0.104 & 20 \\
3 & $10: 90$ & 3.21 & 0.123 & 26 \\
4 & $20: 80$ & 3.22 & 0.134 & 29 \\
5 & $30: 70$ & 3.22 & 0.146 & 33 \\
6 & $40: 60$ & 3.22 & 0.117 & 24 \\
7 & $50: 50$ & 3.23 & 0.111 & 22 \\
\hline
\end{tabular}

The flexural strength of the polymer increases almost linearly with increasing starch content as shown in Table 3. Since starch has a high flexural strength, i.e. it is very flexible. Thus the introduction of starch in polypropylene almost linearly increases the flexural strength of the resulting blend as starch concentration increases. Also, it increases the stiffness of a polymer blends, i.e. it is used as stiffening agent. So, the incorporation of starch to PP enhances the flexural modulus of the material. Flexibility of polymer could be required high depending on its application.

Noteworthy also is the fact that as the starch content increases, the strength at yield tends to approach the strength at break. At around $40 \%$ to $50 \%$ starch concentration, the strength at yield equals the strength at break, thus the material breaks just as it yields. The tensile strength of the material was drastically reduced upon increasing starch content in the $\mathrm{PP} /$ starch blends.

It can also be inferred from Table 3 that the incorporation of starch to Polypropylene reduced meaningfully the elongation at yield or at break of the blends, as compared to the large amount of starch at $40 / 60 \%$ and $50 / 50 \%$. As molecular weight increases, tenacity increases and \% elongation decreases and vice versa. The amount of starch is not important for the values of the latter property, so there are no meaningful variations among the compositions PP/Starch of 40/60 and 50/50. For the same reason as that of tensile strength, the values of elongation at break and at yield almost approach each other as starch content approaches $50 \%$. Such mechanical property like the percentage elongation was not favorable at increasing starch concentration in PP.

Upon analysis of the result of Vicat softening temperature test (Table 3), it can be deduced that the softening temperature lingered almost constantly for starch content below 30\% and then it falls rapidly for concentrations above $30 \%$ due to low resistance to sudden loading. It falls about $20^{\circ} \mathrm{C}$ of its original temperature. The higher the vicat softening point the higher the stiffness. Thus, higher loading of starch makes the resulting polymer less sensitive to heat which could not soften the polymer. It is far below the softening temperature of PP i.e. $160-165^{\circ} \mathrm{C}$. However, there was a slight increment of softening temperature when starch concentration increases slightly from $5 \%$ to $30 \%$.

Table 3. Mechanical Properties of HPIG/starch blends as a function of their compositions.

\begin{tabular}{|c|c|c|c|c|c|c|c|}
\hline \multirow[t]{2}{*}{ S/No } & \multirow{2}{*}{$\begin{array}{c}\text { Composition, } \\
\text { wt } \% \text { starch } / \text { wt } \% \text { HPIG }\end{array}$} & \multicolumn{2}{|c|}{ Tensile Strength, (MPa) } & \multicolumn{2}{|c|}{ \% Elongation } & \multirow{2}{*}{$\begin{array}{c}\text { Flexural Modulus } \\
(\mathrm{MPa})\end{array}$} & \multirow{2}{*}{$\begin{array}{c}\text { Vicat. Temp. } \\
\left({ }^{\circ} \mathrm{C}\right)\end{array}$} \\
\hline & & at Yield & at Break & at Yield & at Break & & \\
\hline 1 & $100 \%$ HPIG110 & 37.6 & 33.0 & 17.0 & 38.7 & 1578 & 154.2 \\
\hline 2 & $5: 95$ & 33.9 & 31.3 & 14.3 & 27.8 & 1630 & 155.3 \\
\hline 3 & $10: 90$ & 31.3 & 28.8 & 12.8 & 21.1 & 1705 & 155.6 \\
\hline 4 & $20: 80$ & 28.5 & 27.0 & 11.3 & 13.6 & 1798 & 156.0 \\
\hline 5 & $30: 70$ & 27.3 & 26.5 & 9.9 & 12.8 & 1854 & 156.5 \\
\hline 6 & $40: 60$ & 30.3 & 30.2 & 8.4 & 9.8 & 2017 & 138.6 \\
\hline 7 & $50: 50$ & 29.0 & 29.0 & 7.2 & 7.4 & 2190 & 135.3 \\
\hline
\end{tabular}

\section{Conclusion}

The inclusion of starch affected some mechanical properties of the polymer positively such as flexural strength, izod impact strength and softening temperatures especially for starch concentrations of $30 \%$ and below. However, there is negative impact on other mechanical properties like tensile strength for concentrations of starch above $30 \%$ and both the melt flow index and percentage elongation for the resulting blend for all concentrations of starch.

Impact Strength increases as the Vicat Softening Point increases. As a result of low softening temperature observed at $40 / 60 \%$ and $50 / 50 \%$ starch/HPIG 110 , the materials could no longer resist sudden load due to high starch content. However, the flexibility of the polymer at higher starch loadings can cause the specimen to break when hammered. Above 30/70\% blends, the impact strength decreases with increase in starch concentration.

The percentage of starch incorporated into HPIG 110 should be low or even below $5 \%$ due to cost advantage. At very low concentration of starch in HPIG 110, the mechanical properties such as tensile strength, percentage elongation, Izod impact strength and flexural modulus, and vicat softening temperature can be maintained at optimal levels depending on the end users application. 


\section{Acknowledgements}

We thank the management of Indorama Eleme Petrochemicals, Port Harcourt, Nigeria for enabling the laboratory tests to be carried out within their facilities.

\section{Reference}

[1] R. Chandra and R. Renu, Biodegradable Polymers, Elsevier Science Ltd, pp. 1273-1335, 1998.

[2] S.C. Zeeman, S.M. Smith and A.M. Smith; Review of starch breakdown in leaves, New Phytologist 163: 247-261, 2004.

[3] V. Viswanath, Degradation studies of polypropylene fibers and nonwovens with prodegradant additives, North Carolina State University, 2010.

[4] S. Zhang, W. Wang H. Wang, W. Qi L. Yue, Q. Yea, Synthesis and characterisation of starch grafted superabsorbent via $10 \mathrm{MeV}$ electron-beam irradiation, J. Carbohydrate Polymers 101, pp. 798-803, 2014.

[5] J.A. Brydson, Flow Properties of Polymer Melts: J. Wiley, New York, 1981.

[6] Chi-Wen Lin, Journals of Materials Science Letters, 2nd edition, vol. 2, pp 46-48, 1993.

[7] F.N. Cogswell, Polymer Melts Rheology, J. of Polymer Science: Polymer Letters Edition, Volume 20, Issue 3, 2004.

[8] C. L. DeLeo and S. S. Velankar, Morphology and rheology of compatibilized polymer blends: diblock compatibilizers vs crosslinked reactive compatibilizers, J. Rheol. 52, pp. 1385-1404, 2008.

[9] C.L. DeLeo, Reactively Compatibilized Starch-Based Renewable Polymer Blends. Swanson School of Engineering, University of Pittsburgh, 2010.

[10] Encyclopedia of Polymer Science and Technology. Starch, John Wiley \& Sons, Inc., 2005.

[11] F. Rodriguez, Principles of Polymer System, 2nd Ed., McGraw Hill, New York, 1983.

[12] A. Rudin, Elements of Polymer Science and Engineering, Academic Press, New York, 1982.

[13] W. Schnabel, Polymer Degradation, Hanser Publisher, 2nd Ed., New York, 1982.

[14] R.B. Seymour and C.E. Carraher, Polymer Chemistry, M. Dekker, New York, 1981.

[15] G. V. Vinogradoo and A. Y. Malkin, Rheology of Polymers, Springer-Verlag, 1980.

[16] V. Gowariher, N.V. Viswanathan and J. Speedhar, Polymer Science, J. Wiley, New York, 1986.

[17] www.epi-global.com: Environmentally degradable plastics based on oxo-biodegradation of conventional polyolefins [homepage on the Internet].

[18] R. Gachter and H. Muller, Plastics Additives, Hanser Publishers, New York, 1985.
[19] G. Pritchard, Additives are essential, in Plastics Additives, Polymer Science and Technology Series Volume 1, pp 3-10, 1998.

[20] D. Hull, Introduction to composite materials, Cambridge University Press, United Kingdom, 1981.

[21] G.J.L. Griffin, Chemistry and technology of biodegradable polymers, Blackle Academic and Professional (Chapman and Hall), Suffolk U.K, 1994.

[22] S. Mortazavi, I. Ghasemi, and A. Oromiehie, Effect of phase inversion on the physical and mechanical properties of low density polyethylene/thermoplastic starch, Polym. Test. 32, pp. 182-191, 2013.

[23] S. Hamdan, D.M.A. Hashim, M. Ahmad, S. Embong, Compatibility studies of polypropylene (PP) -Sago Starch (SS) blends using DMTA, Journal of polymer research, vol. 7, issue 4, pp. 237-244, 2000 .

[24] C. L. Iherika, Experimental study of the effect of starch on the mechanical properties and biodegradation of polypropylene, FUTO, Imo state, Nigeria, 2011.

[25] J.M. Charrier Polymeric Materials and Processing, 'Plastics, Elastomers and Composites', Hanser Publishers, Munich, Vienna, New York, 1991.

[26] A. O. Ogah and J. N. Afiukwa, Effect of starch blend on the mechanical properties and biodegradability of polypropylene; Cont. J. of biological science 5 (1), pp. 20-25, 2011.

[27] J.R.A. Pearson and S.M. Richardson, Computational Analysis of Polymer Processing, Elsevier 1983.

[28] X. Ramis, A. Cadenato, J.M. Salla, J.M. Morancho, A. Valle, S. Contat, A. Ribes, Thermal degradation of polypropylene/starch-based materials, , 2004. Polymer degradation and stability, 86 (3), pp. 483-491, 2004.

[29] S.F. Wang and C.H. Azhari, Morphological-Mechanical property relationship of polypropylene/starch blends, Pakistan Journal of Biological Sciences, vol. 4, Issue 6, pp. 693-695, 2001.

[30] C.H. Azhari and S.F. Wong Review of the morphology-mechanical property relationship of polypropylene/starch blends, Journal of polymer research, vol. 4, issue 2, pp. 215-223, 2001.

[31] A. Whetan, Injection Moulding Machine Elsevier, Applied Science Publisher, London, 1984.

[32] G. W. Lee, M. Park, J. Kim, J. I. Lee and H. G. Yoon, Enhanced Thermal Conductivity of Polymer Composites Filled with Hybrid Filler, Composite A: Applied Science \& Manufacturing, Vol. 37, No. 5, 2006, pp. 727-734.

[33] M. Iza and M. Bousmina, Nonlinear rheology of immiscible polymer blends: step strain experiments, J. Rheol. 44, p. 1363, 2000 .

[34] C. Sailer and U. Handge, Melt viscosity, elasticity, and morphology of reactively compatibilized polyamide 6/styrene-acrylonitrile blends in shear and elongation, Macromolecules, 40, pp. 2019-2028, 2007.

[35] B. Conde-Petit and F. Escher, Complexation induced changes of rheological properties of starch systems at different moisture levels, J. Rheol. 39, p. 1497, 1995. 
[36] G. Della Valle, A. Buleon, P. J. Carreau, P.-A. Lavoie, and B. Vergnes, Relationship between structure and viscoelastic behavior of plasticized starch, J. Rheol. 42, p. 507, 1998.

[37] F. J. Rodriguez-Gonzalez, B. A. Ramsay, and B. D. Favis, Rheological and thermal properties of thermoplastic starch with high glycerol content, Carbohydr. Polym. 58, pp. 139-147, 2004.
[38] S. Voronov, V. Tokarev, K. Oduola and Yu. Lastukhin, Polyperoxide surfactants for interface modification and compatibilization of polymer colloidal systems. I. Synthesis and properties of polyperoxide surfactants, J. Applied Polymer Science. 76(8), pp. 1217-1227, 2000. 